\title{
A phase I radiation dose escalation of stereotactic body radiotherapy for malignant lung tumors
}

\author{
Randi J. Cohen ${ }^{1}$, Navesh K. Sharma ${ }^{1}$, Jian Q. (Michael) Yu ${ }^{2}$, Lu Wang ${ }^{1}$, Mark K. Buyyounouski ${ }^{1}$, \\ Michael Unger ${ }^{3}$, Hossein Borghaei ${ }^{4}$, Earl King ${ }^{3}$, Walter Scott ${ }^{5}$, Elaine Callahan ${ }^{1}$, Benjamin J. Movsas ${ }^{6}$, \\ Steven J. Feigenberg ${ }^{7}$
}

\footnotetext{
${ }^{1}$ Department of Radiation Oncology, Fox Chase Cancer Center, Philadelphia, USA;

${ }^{2}$ Department of Diagnostic Imaging, Fox Chase Cancer Center, Philadelphia, USA;

${ }^{3}$ Department of Pulmonary Medicine, Fox Chase Cancer Center, Philadelphia, USA;

${ }^{4}$ Department of Medical Oncology, Fox Chase Cancer Center, Philadelphia, USA;

${ }^{5}$ Department of Surgical Oncology, Fox Chase Cancer Center, Philadelphia, USA;

${ }^{6}$ Department of Radiation Oncology, Henry Ford Hospital, Detroit, USA;

${ }^{7}$ Department of Radiation Oncology, University of Maryland, Baltimore, USA.

Email: sfeigenberg@umm.edu
}

Received 15 January 2010; revised 25 January 2010; accepted 30 January 2010.

\begin{abstract}
Objectives: This Phase I study determines the maximum tolerated dose (MTD) of stereotactic body radiotherapy (SBRT) for lung tumors. Methods: Eligible patients had biopsy proven cancer with a maximum tumor size $\leq 5 \mathrm{~cm}$. Total doses were escalated from 40 to 48 , then to $56 \mathrm{~Gy}$, delivered in 4 equal fractions administered 2 to 3 times per week on an IRB approved protocol. SBRT was administered using 5 to 9 fixed beam arrangements with CT localization. Internal target volumes (ITV) were based on breath hold scans or 4D CT simulation. The planning target volume (PTV) was defined as the ITV with a uniform $5 \mathrm{~mm}$ expansion. Dose limiting toxicity (DLT) was defined as any grade 3 or higher toxicity using the Radiation Therapy Oncology Group (RTOG) common toxicity criteria (CTC). Results: Between April 2004 and February 2008, 18 patients received the prescribed treatment ( $40 \mathrm{~Gy} \mathrm{n}=6,48 \mathrm{~Gy} \mathrm{n}=7$, $56 \mathrm{~Gy} \mathbf{n}=5$ ). Seventeen of 18 patients had non-small cell lung cancer ( 1 with rectal cancer), four of whom were treated for an oligometastasis. The median age of the patients was 68, while the median Karnofsky performance status was 90 . The mean tumor size was $2.6 \mathrm{~cm}$ (range 0.9 to $4.5 \mathrm{~cm}$ ). One grade 3 pulmonary event occurred (at $48 \mathrm{~Gy}$ dose level) immediately following treatment with the onset of fever and shortness of breath that responded to antibiotics. No other DLTs occurred. Conclusions: SBRT utilizing patient specific target volumes without gating appears safe. The maximum tolerated dose was not reached.
\end{abstract}

Keywords: Stereotactic Body Radiotherapy; Phase I; Dose Escalation; Prospective; Lung Cancer

\section{INTRODUCTION}

The standard therapy for early stage non-small cell lung cancer (NSCLC) is surgery [1]. Radiation therapy (RT) can similarly cure early stage NSCLC, but has less favorable outcomes due to competing causes of death, lack of pathologic staging and/or less efficacious treatment. With conventional radiation doses (i.e. 60-70 Gy) local failure is considerable and may be underestimated based on the method of follow-up with the highest failure rate reported by bronchoscopy. [2] Due to this unacceptable local failure rate, many institutions have designed trials to improve local control. [3-5] At the University of Michigan, Martel et al. [6] determined that the total radiation dose required to achieve a $>50 \%$ probability of local control using conventional fractionation (i.e. 2 Gy per fraction) was $>84$ Gy and a phase I study was completed treating tumors to over $100 \mathrm{~Gy}$. The major problem with this treatment strategy is the duration of therapy (2 to $2 \frac{1}{2}$ months). As an alternative, investigators have evaluated accelerating the dose of radiation through hypofractionation [7] which increases the radiobiologic effective dose by decreasing treatment time.

Stereotactic radiosurgery is an extreme version of hypofractionation that has become an established alternative to surgery for selecting brain tumors. [8] More recently, this technique has been adopted for treating tumors outside the brain. [9-18] Unlike radiosurgery for intracranial targets, stereotactic body radiotherapy (SB$\mathrm{RT}$ ) is complicated by less precise target definition and internal organ motion, which requires a margin to ensure 
coverage of the target volume. Solutions include improving immobilization (i.e. stereotactic body frames), reducing or monitoring internal organ motion (i.e. respiratory gating, active breathing control, or breath holding), reducing daily set-up uncertainties (i.e. Computed Tomography, CT, localization prior to treatment, electronic portal imaging with fiducial markers placed in the tumor) or fractionation. Even with all of these innovative techniques, most investigators use axial margins of at least $5 \mathrm{~mm}$ and a cranial-caudal margin of 5 to $10 \mathrm{~mm}$ around the gross tumor volume (GTV) to account for set-up error and organ motion (i.e. planning target volume, PTV) $[9,18]$ with no additional margin for subclinical disease (i.e. clinical target volume, CTV).

When this study was developed, there were only two prospective phase I studies in the literature. Herfarth et al. [19] published results using SBRT in the liver in 2001. Timmerman et al. [16] reported their initial results at ASCO in 2002 for medically inoperable non-small cell lung cancer (NSCLC) patients with tumors $<7 \mathrm{~cm}$ and no evidence of lymph node involvement. The patients were treated with 3 fractions over 7 to 8 days starting at 800 cGy per fraction which was escalated to 2000 cGy per fraction. Only 2 of 36 patients developed grade 3 pulmonary toxicity (one $\mathrm{T} 1$ and one $\mathrm{T} 2$ tumor) and the maximum tolerated dose (MTD) was not reached. Patients were immobilized in a stereotactic body frame as originnally described by Blomgren and Lax, [9] who defined the PTV as an expansion of $5 \mathrm{~mm}$ in the axial dimension and $1 \mathrm{~cm}$ in the cranial caudal directions.

Fukumoto et al. [10] estimated the target volume by obtaining 3 CT scans during different respiratory phases, simulating a "slow CT" technique. The first scan was performed during normal respiration, while the $2^{\text {nd }}$ and $3^{\text {rd }}$ were obtained during maximum inhalation and exhalation, respectively. The combination of the 3 scans accurately described the gross tumor volume and its tumor specific motion. Unlike our current trial, Fukumoto et al., did not use a stereotactic body frame for simulation and treatment nor did they perform imaging prior to treatment to improve daily localization and reproducibility. In their trial, the PTV was created by adding $10 \mathrm{~mm}$ margins to the GTV. Patients were treated with a very conformal technique to a total dose of 48 or 60 Gy in 8 fractions. This technique is ideal for a frail patient population because it limits treatment time and reduces patient discomfort.

Given the limited data in 2002, a phase I study was designed to examine the role of SBRT using 3D image guided radiotherapy and tumor specific targets motion ("slow CT"). The primary goal at the initiation of this study was to develop a treatment equivalent to approximately 70 Gy at conventional fractionation with planned dose escalations to $100 \mathrm{~Gy}$ (as treated in the Michigan series) with a 4 fraction regimen. The following paper describes the final results of our phase I dose escalation trial.

\section{METHODS \& MATERIALS}

Prior to the enrollment of any patient, the protocol and consent form were reviewed and approved by an internal Research Review Committee and Institutional Research Review Board at Fox Chase Cancer Center. Patients described in this manuscript willingly participated on this prospective series. To be included in the study, patients had to have one or two tumors in the lung (primary NSCLC or metastatic) with a maximum diameter of $5 \mathrm{~cm}$. Patients were required to undergo a pathologic diagnosis prior to enrollment. Local recurrences following wedge resections were allowed if biopsy-proven. Patients had to have a Karnofsky Performance Status of 60 or higher. Central tumors were not excluded. Pulmonary function tests were obtained prior to radiotherapy, although there was no restriction based on pulmonary status. Of the 18 patients, 13 were unfit for surgical treatment due to poor pulmonary function and/or other medical comorbidities and five refused surgery.

\subsection{Treatment Policy}

Patients were immobilized in a FDA approved stereotactic body frame (Integra Radionics, Burlington, MA, USA) that employs a rigid frame and vacuum pillow. This particular immobilization device does not use abdominal compression to limit respiratory motion. Patient initial positioning was reproduced based on tattoos at the upper and lower level of the vacuum pillow as well as at the isocenter. Planning CT scans in the stereotactic body frame were obtained to get stereotactic coordinates. For ten patients, three CT scans were obtained: one during normal respiration, one during maximum end expiration, and one during maximum end inspiration, as per Fukumoto et al., [10] to obtain an accurate representation of the tumor motion (i.e. internal target volume, ITV) during the respiratory cycle. CT scans were fused on their bony landmarks. The last seven patients underwent a 4 dimensional CT (4DCT) simulation to generate an ITV. $[13,20,21]$ One patient underwent both 4DCT simulation and scans using the breath holding technique. Axial images were obtained every 2.5 or $3 \mathrm{~mm}$ through the entire thorax. The GTV was identified on each of the axial CT imaging using pulmonary windows. Only the solid tumor component was targeted. Spiculations were not contoured.

For patient's simulated with multiphase CT scans (inspiration, expiration, and free breathing), the ITV was defined by combining the GTVs outlined in each of the three CT scans. When 4DCT was used, the ITV was defined from a reconstructed data set generated using the maximum-intensity-projection (MIP) protocol. MIP creates a 3D CT scan which represents the greatest voxel 
intensity values throughout the 4D CT data-set. The CTV was defined as the ITV with no additional margin to account for subclinical disease. The PTV incorporated the ITV plus $5 \mathrm{~mm}$ in all directions to account for set-up error. Final patient positioning was achieved using CT localization prior to each treatment using the PRIMATOM sliding CT gantry (Siemens Medical Solutions, Concord, CA, USA) for fifteen patients and on board cone beam CT technology (Varian Medical Systems, Palo Alto, CA, USA) for three patients.

Treatment planning was delivered using the Radionics ${ }^{\mathrm{TM}}$ stereotactic planning system (Integra Radionics) using 5 to 9 coplanar or non-coplanar, non-opposing beams. No patient was treated using intensity modulation. The distance between the block edge and the PTV for each of the beams eye's view was 3 to $4 \mathrm{~mm}$ to ensure the $90 \%$ isodose line would cover the PTV (i.e. dose prescribed to $90 \%$ isodose line). This will allow a very steep fall off in the dose outside of the PTV potentially maximizing the benefit of a rapid fall off in the dose while minimizing the hot spots in the surrounding normal tissue.[22] Heterogeneity corrections were used.

As part of the dose escalation protocol, the first cohort of patients received 4000 cGy in 4 fractions with the radiation delivered on non-consecutive days either 2 or 3 times a week at 1000 cGy per fraction. This dose was chosen since it was radiobiologically equivalent to approximately 70 Gy at 2 Gy per fraction, the dose utilized off study at our institution. Biologically equivalent doses (BED) were calculated using the formula BED $=$ nd $(1+d /(\alpha / \beta))$, where $\mathrm{n}=$ number of fractions; $\mathrm{d}=$ daily fraction size; and $\alpha / \beta=10$. The total treatment dose of each subsequent cohort was escalated an additional 800 cGy at 200 cGy per fraction, i.e., 4800 cGy and then 5600 cGy in 4 fractions. The final dose was chosen as it is similar to the highest dose reached on the University of Michigan 3D dose escalation trial [4]. A three month period of observation after the sixth patient in each of the first two cohorts was performed prior to escalating the dose to ensure no adverse events occurred.

The primary endpoint of the study was to determine the maximum tolerated dose (MTD) for treating malignant tumors of the lung with SBRT. The secondary endpoint was to determine the response rate, local control and PET response at 3 months (for those treated definitely) for these patients undergoing SBRT.

\subsection{Statistics}

The dose escalation followed the method described in Babb et al. [23] and shown to be Bayesian-feasible, Bayesian-optimal and consistent by Zacks et al. [24]. The dose for each cohort was determined so that, on the basis of all available data, the probability that it exceeds the MTD is equal to a pre-specified value $\alpha$. For the first cohort $\alpha=0.25$, for the second cohort $\alpha=0.35$, and for the third cohort $\alpha=0.5$. A maximum of 18 patients were planned for accrual to this trial.

\subsection{Follow-Up after Treatment}

All patients underwent a CT scan and pulmonary function tests one month following therapy. A PET scan was obtained prior to and 3 months following treatment for patients treated with curative intent with primary NSCLC to determine the biologic response which potentially could act as an early surrogate of local failure (reported elsewhere). Subsequently, CT scans were obtained every 3 months until 2 years. Other investigations were obtained based on clinical indication. Progressive disease was defined per the RECIST criteria: [25] at least a 20\% increase in the sum of longest diameter (LD) of the treated lesion taking as reference the smallest sum LD recorded since the treatment started.

\section{RESULTS}

Between April 2004 and February 2008, 18 patients with 19 tumors received the prescribed treatment. Patient characteristics of this cohort are described in Table 1. Seventeen of the 18 patients had NSCLC, while one patient had metastatic rectal cancer. The rectal cancer patient had stable extra-pulmonary disease and was treated to 2 lung metastases during the same session. Four patients with NSCLC were treated for oligometastatic disease. The median age of the patients was 68 years (range 48 to 82), while the median Karnofsky performance status was 90 (range 60 to 100). The mean tumor size was $2.0 \mathrm{~cm}$ (range 0.9 to $4.5 \mathrm{~cm}$ ). Prior to SBRT, half of patients treated had received prior radiotherapy, surgery and/or chemotherapy to the lung. Six patients were on oxygen prior to SBRT. The mean pre-treatment FEV1 was 1.41 liters (range 0.49 to $2.6 \mathrm{~L}$ ), while the mean DLCO was $52 \%$ of predicted (range 30 to $90 \%$ ). The mean post-treatment pulmonary function tests were not significantly different from the pre-treatment tests (mean FEV1 $=1.25 \mathrm{~L}$, mean DLCO $=50.8 \%$ ).

With a median follow-up of 24 months (range 3 months to 48 months), most patients (72\%) did not experience any adverse side effects during or following treatment. No patients experienced chest wall pain, rib fracture, esophageal stricture, nausea, subcutaneous fibrosis or brachial plexopathy. The most common grade 2 or higher side effect reported was fatigue, which was seen in 3 patients between one and three months following the completion of treatment. Two patients experience grade 2 erythema within the first month following treatment.

Two patients experienced pneumonitis, one that was grade 2 and one that was grade 3. Both patients had been previously treated with chemotherapy and radiation prior to SBRT for an oligometastasis. The one grade 3 event 
Table 1. Patient characteristics.

\begin{tabular}{|c|c|c|c|c|c|c|c|c|c|c|c|c|c|c|c|c|}
\hline Pt \# & Age & Race & $\begin{array}{l}\text { Gen- } \\
\text { der }\end{array}$ & $\begin{array}{l}\text { Total } \\
\text { Dose }\end{array}$ & $\begin{array}{c}\text { Primary } \\
\text { Site }\end{array}$ & $\begin{array}{c}\text { Tumor } \\
\text { Location }\end{array}$ & Histology & $\begin{array}{l}\text { Stage at } \\
\text { Dx }\end{array}$ & $\begin{array}{l}\text { Prior } \\
\text { Therapy }\end{array}$ & $\begin{array}{l}\text { Local } \\
\text { Failure }\end{array}$ & $\begin{array}{l}\text { Grade } \\
3 \text { SAE }\end{array}$ & Pre & $\begin{array}{l}\text { Post } \\
\text { r } \\
\text { rs) }\end{array}$ & & & $\begin{array}{l}\text { Tumor } \\
\text { (cm) }\end{array}$ \\
\hline 1 & 74 & W & M & 40 Gy & Lung & LUL & $\begin{array}{l}\text { Squamous Cell } \\
\text { Carcinoma }\end{array}$ & T4N0M0 & Chemo & YES & No & 0.95 & 0.92 & 44 & 46 & 1.7 \\
\hline 2 & 69 & W & M & 40 Gy & Lung & LLL & $\begin{array}{l}\text { Adenocarci- } \\
\text { noma }\end{array}$ & T1N0M0 & None & YES & No & 1.06 & 1.28 & 30 & 31 & 1.5 \\
\hline 3 & 52 & W & F & 40 Gy & Lung & LUL & $\begin{array}{l}\text { Large Cell } \\
\text { Carcinoma }\end{array}$ & T2N2M0 & $\begin{array}{c}\text { Surgery } \\
\text { Radiation }\end{array}$ & No & No & 1.81 & 1.70 & 54 & 56 & 1 \\
\hline 4 & 79 & W & F & 40 Gy & Lung & RML & $\begin{array}{l}\text { Bronchiolo- } \\
\text { Alveolar Ca }\end{array}$ & T1N0M0 & Surgery & No & No & 0.91 & 0.82 & 59 & 62 & 2 \\
\hline 5 & 71 & W & M & 40 Gy & Lung & RUL & $\begin{array}{l}\text { Adenocarci- } \\
\text { noma }\end{array}$ & T1N0M0 & Radiation & No & No & 2.26 & $\mathrm{X}$ & 43 & $X$ & 1 \\
\hline 6 & 61 & W & F & 40 Gy & Lung & LUL & $\begin{array}{l}\text { Adenocarci- } \\
\text { noma }\end{array}$ & T1N0M0 & None & No & No & 1.14 & 1.18 & 38 & 35 & 2 \\
\hline 7 & 48 & W & $\mathrm{F}$ & 48 Gy & Lung & RUL & $\begin{array}{l}\text { Squamous Cell } \\
\text { Carcinoma }\end{array}$ & T1N0M0 & $\begin{array}{l}\text { Surgery, } \\
\text { Radiation, } \\
\text { Chemo }\end{array}$ & YES & YES & 1.41 & 1.22 & 42 & 52 & 1.4 \\
\hline 8 & 57 & W & M & $48 \mathrm{~Gy}$ & Lung & RUL & $\begin{array}{l}\text { Adenocarci- } \\
\text { noma }\end{array}$ & T2N1M0 & $\begin{array}{l}\text { Surgery, } \\
\text { Radiation, } \\
\text { Chemo }\end{array}$ & YES & No & 2.6 & $\mathrm{X}$ & 64 & $X$ & 2.1 \\
\hline 9 & 69 & W & F & 48 Gy & Lung & RUL & $\begin{array}{l}\text { Adenocarci- } \\
\text { noma }\end{array}$ & T1N0M0 & None & YES & No & 0.94 & 1.05 & 40 & 49 & 1.5 \\
\hline 10 & 80 & W & M & 48 Gy & Lung & RUL & $\begin{array}{l}\text { Squamous Cell } \\
\text { Carcinoma }\end{array}$ & T1N0M0 & None & No & No & 1.62 & 1.73 & 68 & 75 & 2.3 \\
\hline 11 & 65 & W & F & $48 \mathrm{~Gy}$ & Rectum & $\begin{array}{l}2 \text { lesions } \\
\text { in LUL }\end{array}$ & $\begin{array}{l}\text { Adenocarci- } \\
\text { noma }\end{array}$ & T3N0M0 & Surgery & No & No & 0.69 & 0.68 & 43 & 39 & $\begin{array}{l}3.1 \\
1.5\end{array}$ \\
\hline 12 & 78 & W & M & $48 \mathrm{~Gy}$ & Lung & LUL & $\begin{array}{l}\text { Squamous Cell } \\
\text { Carcinoma }\end{array}$ & T1N0M0 & None & No & No & 1.99 & X & 90 & $X$ & 1.1 \\
\hline 13 & 82 & W & M & 48 Gy & Lung & RLL & $\begin{array}{l}\text { Squamous Cell } \\
\text { Carcinoma }\end{array}$ & T1N0M0 & None & No & No & 0.71 & $\mathrm{X}$ & 67 & $\mathrm{X}$ & 2.7 \\
\hline 14 & 68 & W & M & 56 Gy & Lung & RLL & $\begin{array}{l}\text { Squamous Cell } \\
\text { Carcinoma }\end{array}$ & T2N0M0 & Surgery & YES & No & 2.4 & 2.38 & 70 & 67 & 2.5 \\
\hline 15 & 74 & B & M & 56 Gy & Lung & RUL & $\begin{array}{l}\text { Bronchiolo- } \\
\text { Alveolar Ca }\end{array}$ & T2N0M0 & None & No & No & 1.47 & $\mathrm{X}$ & 52 & $\mathrm{X}$ & 4.5 \\
\hline 16 & 59 & B & F & 56 Gy & Lung & RUL & $\begin{array}{l}\text { Adenocarci- } \\
\text { noma }\end{array}$ & T1N0M0 & None & No & No & 0.49 & 0.51 & 33 & 24 & 1.7 \\
\hline 17 & 68 & W & M & 56 Gy & Lung & LLL & $\begin{array}{l}\text { Squamous Cell } \\
\text { Carcinoma }\end{array}$ & T1N0M0 & None & No & No & 1.8 & 1.59 & 64 & 57 & 1.2 \\
\hline 18 & 69 & W & F & 56 Gy & Lung & RLL & $\begin{array}{l}\text { Non-Small Cell } \\
\text { NOS }\end{array}$ & T1N0M0 & Surgery & No & No & 1.13 & 1.18 & 46 & 68 & 3.1 \\
\hline
\end{tabular}

W: White

LUL: Left Upper Lobe

RUL: Right Upper Lobe
B: Black

LLL: Left Lower Lobe

RLL: Righe Lower Lobe
X: One month post-SBRT PFTs not performed RML: Right Middle Lobe was previously treated for an advanced non-small lung cancer requiring induction chemotherapy and radiation followed by left sided pneumonectomy. She developed a second primary versus an oligometastasis in the contra- lateral right upper lobe that was treated with a wedge resection. She had a biopsy-proven local recurrence in the staple line, which was treated to 4800 cGy (see Figure 1 which illustrates the dose distribution). A fever developed 


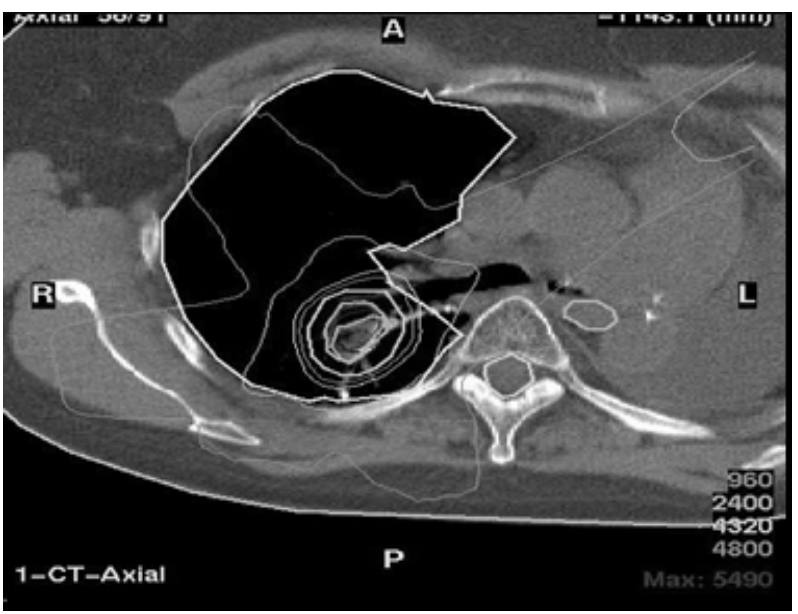

Figure 1. This is an axial CT image from the patient's simulation illustrating the prescription isodose line (48 Gy), as well as $90 \%, 50 \%$ and $20 \%$ of the prescription. This patient had prior induction chemoradiation followed by a pneumonectomy. She subsequently developed a second primary in the right upper lobe. This was treated with a wedge resection, which recurred locally. Her centrally-located, biopsy-proven local recurrence in the staple line was treated to $48 \mathrm{~Gy}$.

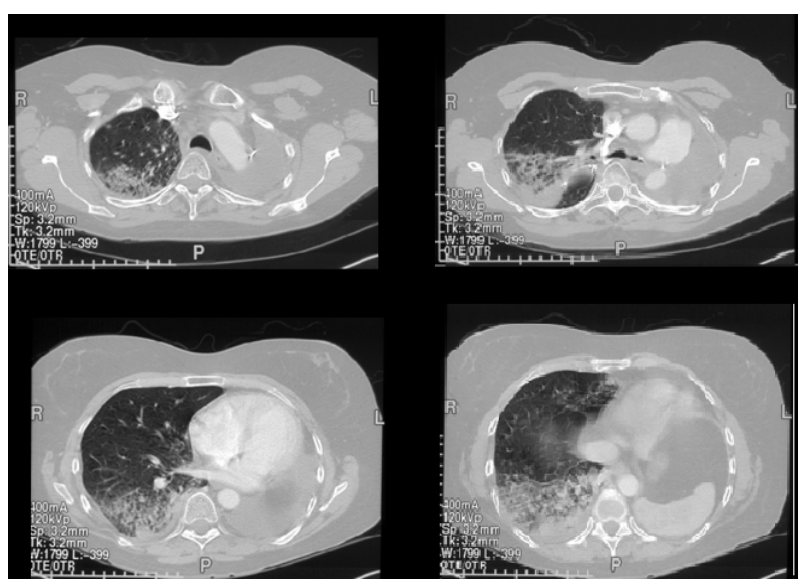

Figure 2. These CT slices were obtained one week following admission to the hospital which was required due to the development of fever of $103^{\circ} \mathrm{F}$ and shortness of breath one day following SBRT while on oral antibiotics. These images demonstrate the trilobar pneumonia.

after the first fraction. She was empirically treated with oral antibiotics and the fever resolved. The day after the final fraction, she developed a fever up to $103^{\circ} \mathrm{F}$ with increasing shortness of breath. She required admission to the hospital and a stay in the ICU for a tri-lobar pneumonia (see Figure 2). She remained hospitalized for a week and responded to intravenous antibiotics and supportive care. Her respiratory function continued to improve over time, although she remained intermittently oxygen dependent 16 months following treatment. Unfortunately, she developed a failure on the staple line $2 \mathrm{~cm}$ from the site treated.
No patient who received 56 Gy developed a symptomatic pulmonary injury, although one patient developed asymptomatic distal atelectasis for a peripherally treated tumor six months following radiation.

\subsection{Local Control}

Six patients developed a local failure. There were no marginal failures outside of the original PTV. Only two of the local failures were biopsy proven. One of the patients was treated for a gross recurrence following a wedge resection and developed a recurrence on the staple line $2 \mathrm{~cm}$ from the treated lesion. The second biopsy-proven failure occurred in patient number 1 , who had very poor pulmonary function and presented with 2 tumors in the same lobe (i.e. T4). That individual was initially treated palliatively with chemotherapy alone (six cycles of carboplatin and paclitaxel). The smaller tumor resolved and the larger tumor shrank from 4 to $2 \mathrm{~cm}$. The post-chemotherapy volume of the larger tumor was treated on study. Six months following this second treatment, an area of nodularity developed outside the original PTV, but retrospectly was in the original pre-chemotherapy GTV. The tumor that initially resolved on chemotherapy returned 14 months later. That lesion was treated off-study with SBRT.

\section{DISCUSSION}

There are many reports on SBRT in the literature although there are very few prospective trials. The morbidity results in our study are lower than recently published trials and seem more impressive in light of this heavily pretreated population. One could argue that the only grade 3 event described in this trial may not relate to the radiotherapy.

Baumann et al. [26] reported a $21 \%$ incidence of grade 3 toxicities of the 60 patients treated at the Karolinska University Hospital in Sweden. They prescribed $45 \mathrm{~Gy}$ in 3 fractions to the $67 \%$ isodose line (19 Gy when corrected to 80\%) [26,27]. Fakiris et al. [28] updated the Indiana University phase II trial demonstrating an $11.4 \%$ rate of grade 3 to 5 events occurring in peripherally located tumors and $27.3 \%$ in their centrally located patients. The dose in the Indiana experience was $60 \mathrm{~Gy}$ in 3 fractions prescribed to the $80 \%$ isodose line. However, since heterogeneity corrections were not used, the actual prescribed dose has now been reported to be closer to 18 Gy per fraction. [16]

Nagata et al. [14] reported a phase I/II study using 48 Gy in 4 fractions in 45 patients with no grade 3 or higher pulmonary events and excellent local control. In the largest series reported, Onishi et al. [29,30] reported a $2.4 \%$ incidence of grade 3 and 4 pneumonitis and no grade 5 events. In fact, there have been only $14(0.6 \%)$ reported grade 5 events from a Japanese National Survey out of 2104 patients treated (personal communication) compared to 5 of 70 treated on the phase II experience 
from Indiana.

Other possible morbidities following SBRT are chest wall pain and rib fracture. Onishi et al. [29] described the multi-institutional Japanese experience and reported a $0.8 \%$ incidence of rib fractures. The Princess Margaret group [31] demonstrated a $48 \%$ incidence of rib fracture in peripheral lesions treated with 54-60 Gy in 3 fractions. Ribs in the areas of the fracture generally received $43 \mathrm{~Gy}$ and the tumor was less than $5 \mathrm{~mm}$ from the rib. The Colorado and Virginia groups [32] combined their experience of peripheral tumors less than $1.5 \mathrm{~cm}$ from the chest wall. The risk of chest wall pain and/or fracture correlated with the volume of chest wall receiving more than $30 \mathrm{~Gy}$. The incidence was $0 \%(0 / 4), 33 \%(2 / 6), 46 \%$ (6/13) and 63\% (5/8) for < 10 cc, 10.1-40 cc, 40.1-120 сc and $>120 . c c$, respectively. The author recommended the use of $48 \mathrm{~Gy}$ in 4 fractions when the tumor was adjacent to the rib. None of the patients treated on this trial developed rib fracture or chest wall pain.

The Cleveland Clinic [33] reported the most compelling study that evaluated two different fractionation schemas (50 Gy in 5 fractions versus $60 \mathrm{~Gy}$ in 3 fractions). When their program started, a 5 fraction regimen was used. In 2000, after the RTOG study was opened, the Timmerman approach (60 Gy in 3 fractions) was followed. With short follow-up, local control was similar between the two schemas (97\% versus $100 \%)$ although the chest wall toxicity was significantly more with $60 \mathrm{~Gy}$. The incidence of chest wall pain was $4 \%(2 / 56)$ for $50 \mathrm{~Gy}$ and $18 \%$ (7/38) for $60 \mathrm{~Gy}, \mathrm{p}=0.028$. Also, given the median follow-up of only 9 months in the 60 Gy cohorts, the morbidity is likely to increase with further follow-up.

Brachial plexopathy (BP) is a rare event following SBRT. The Indiana University [34] experience described seven brachial plexus injuries. Four patients had grade 2, two patients had grade 3 and one had grade $4 \mathrm{BP}$. The authors tried to determine dose volume relation of apical tumors, which they defined as being located superior to the arch of the aorta (37 of 273 cases). Using the subclavian and axillary vessels as a surrogate for the brachial plexus dose, when the dose was greater than the median dose (26 Gy over 3 fractions) the 2 year incidence of BP was $46 \%$ versus $8 \%(p=0.038)$ for lower doses. There were no brachial plexus injuries in our study.

Currently, there are 2 predominant fractionation schemas for SBRT of malignant lung tumors: the Japanese approach $(12 \mathrm{~Gy} \times 4)$ [14] and the RTOG approach developed by Timmerman $(20 \mathrm{~Gy} \times 3)$. $[16,20,35]$ The biologic effective dose (BED) between the 2 schemas are drastically different (105.6 versus $180 \mathrm{~Gy}$ ), but there are no clear differences in local control (85\% versus $88 \%)$. The calculation of the BED from conventional to hyopfractionated radiation schedules, however, may be flawed. [36]

Our local control appears similar to what others describe although two of the failures are important to comment on. The tumors of patients treated in the post-operative or post-chemotherapy setting may be difficult to delineate. Therefore, these patients may not be ideal candidates for SBRT. Such is the case for the two previously described patients who had biopsy-proven local failures-the first being the patient who had a local recurrence along a wedge resection staple line and the second being the patient who had a recurrence in the pre-chemotherapy volume, although the post-chemotherapy volume was treated. Determining appropriate target volumes may be more difficult after either surgical intervention or chemotherapy. Unfortunately, the larger volumes necessary to cover all these areas of subclinical disease may increase morbidity. [37] Therefore, in post-surgical and post-chemotherapy settings, care must be taken to weigh the risks and benefits of this treatment following prior treatment.

In conclusion, SBRT utilizing patient specific target volumes without gating appears safe. In our study, patient simulation was carefully performed to create an ITV. A stereotactic body frame was utilized and imaging was obtained prior to each treatment to verify patient position. One grade 3 pulmonary event occurred at the 48 Gy dose levels, which may be related to radiotherapy. No other dose limiting toxicities occurred. There was no significant decrement in pulmonary function tests following SBRT. The maximum tolerated dose in this study was not reached.

\section{REFERENCES}

[1] Mountain, C.F. (1997) Revisions in the international system for staging lung cancer. Chest, 111, 1710-1717.

[2] LeChevalier, T. et al. (1991) Radiotherapy alone versus combined chemotherapy and radiotherapy in nonresectable non-small-cell lung cancer: First analysis of a randomized trial in 353 Patients. Journal of the National Cancer Institute, 83, 417-423.

[3] Bradley, J., Graham, M.V., Winter, K., Purdy, J.A., Komaki, R., Roa, W.H., Ryu, J.K., Bosch, W. and Emami, B. (2005) Toxicity and outcome results of RTOG 9311: A phase I-II dose-escalation study using three-dimensional conformal radiotherapy in patients with inoperable nonsmall-cell lung carcinoma. International Journal of Radiation Oncology Biology Physics, 61, 318-328.

[4] Narayan, S., Henning, G.T., Ten Haken, R.K., Sullivan, M.A., Martel, M.K. and Hayman, J.A. (2004) Results following treatment to doses of 92.4 or 102.9 Gy on a phase I dose escalation study for non-small cell lung cancer. Lung Cancer, 44, 79-88.

[5] Rosenzweig, K.E., Fox, J.L., Yorke, E., Amols, H., Jackson, A., Rusch, V., Kris, M.G., Ling, C.C. and Leibel, S.A. (2005) Results of a phase I dose-escalation study using three-dimensional conformal radiotherapy in the treatment of inoperable nonsmall cell lung carcinoma. Cancer, 
103, 2118-2127.

[6] Martel, M.K., Ten Haken, R.K., Hazuka, M.B., Kessler, M.L., Strawderman, M., Turrisi, A.T., Lawrence, T.S., Fraass, B.A. and Lichter, A.S. (1999) Estimation of tumor control probability model parameters from 3-D dose distributions of non-small cell lung cancer patients. Lung Cancer, 24, 31-37.

[7] Mehta, M., Scrimger, R., Mackie, R., Paliwal, B., Chappell, R. and Fowler, J. (2001) A new approach to dose escalation in non-small-cell lung cancer. International Journal of Radiation Oncology Biology Physics, 49, 2333.

[8] Andrews, D.W., Scott, C.B., Sperduto, P.W., Flanders, A.E., Gaspar, L.E., Schell, M.C., Werner-Wasik, M., Demas, W., Ryu, J., Bahary, J.P., Souhami, L., Rotman, M., Mehta, M.P. and Curran, W.J.Jr. (2004) Whole brain radiation therapy with or without stereotactic radiosurgery boost for patients with one to three brain metastases: phase III results of the RTOG 9508 randomised trial. Lancet, 363, 1665-1672.

[9] Blomgren, H., Lax, I., Naslund, I. and Svanstrom, R. (1995) Stereotactic high dose fraction radiation therapy of extracranial tumors using an accelerator. Clinical experience of the first thirty-one patients. Acta Oncologica, 34, 861-870.

[10] Fukumoto, S., Shirato, H., Shimzu, S., Ogura, S., Onimaru, R., Kitamura, K., Yamazaki, K., Miyasaka, K., Nishimura, M. and Dosaka-Akita, H. (2002) Small-volume image-guided radiotherapy using hypofractionated, coplanar, and noncoplanar multiple fields for patients with inoperable Stage I nonsmall cell lung carcinomas. Cancer, 95, 1546-1553.

[11] Hara, R., Itami, J., Kondo, T., Aruga, T., Abe, Y., Ito, M., Fuse, M., Shinohara, D., Nagaoka, T. and Kobiki, T. (2002) Stereotactic single high dose irradiation of lung tumors under respiratory gating. Radiotherapy and Oncology, 63, 159-163.

[12] Harada, T., Shirato, H., Ogura, S., Oizumi, S., Yamazaki, K., Shimizu, S., Onimaru, R., Miyasaka, K., Nishimura, M. and Dosaka-Akita, H. (2002) Real-time tumortracking radiation therapy for lung carcinoma by the aid of insertion of a gold marker using bronchofiberscopy. Cancer, 95, 1720-1727.

[13] Herfarth, K.K., Debus, J., Lohr, F., Bahner, M.L., Fritz, P., Hoss, A., Schlegel, W. and Wannenmacher, M.F. (2000) Extracranial stereotactic radiation therapy: Set-up accuracy of patients treated for liver metastases. International Journal of Radiation Oncology Biology Physics, 46, 329335.

[14] Nagata, Y., Takayama, K., Matsuo, Y., Norihisa, Y., Mizowaki, T., Sakamoto, T., Sakamoto, M., Mitsumori, M., Shibuya, K., Araki, N., Yano, S. and Hiraoka, M. (2005) Clinical outcomes of a phase I/II study of 48 Gy of stereotactic body radiotherapy in 4 fractions for primary lung cancer using a stereotactic body frame. International Journal of Radiation Oncology Biology Physics, 63, 1427-1431.

[15] Negoro, Y., Nagata, Y., Aoki, T., Mizowaki, T., Araki, N., Takayama, K., Kokubo, M., Yano, S., Koga, S., Sasai, K., Shibamoto, Y. and Hiraoka, M. (2001) The effectiveness of an immobilization device in conformal radiotherapy for lung tumor: reduction of respiratory tumor movement and evaluation of the daily setup accuracy. International Journal of Radiation Oncology Biology Physics, 50, 889-898.

[16] Timmerman, R., Papiez, L., McGarry, R., Likes, L., DesRosiers, C., Frost, S. and Williams, M. (2003) Extracranial stereotactic radioablation: Results of a phase I study in medically inoperable stage I non-small cell lung cancer. Chest, 124, 1946-1955.

[17] Uematsu, M., Shioda, A., Tahara, K., Fukui, T., Yamamoto, F., Tsumatori, G., Ozeki, Y., Aoki, T., Watanabe, M. and Kusano, S. (1998) Focal, high dose, and fractionated modified stereotactic radiation therapy for lung carcinoma patients: A preliminary experience. Cancer, 82, 10621070.

[18] Wulf, J., Hadinger, U., Oppitz, U., Olshausen, B. and Flentje, M. (2000) Stereotactic radiotherapy of extracranial targets: CT-simulation and accuracy of treatment in the stereotactic body frame. Radiotherapy and Oncology, 57, 225- 236.

[19] Herfarth, K.K., Debus, J., Lohr, F., Bahner, M.L., Rhein, B., Fritz, P., Hoss, A., Schlegel, W. and Wannenmacher, M.F. (2001) Stereotactic single-dose radiation therapy of liver tumors: Results of a phase I/II trial. Journal of Clinical Oncology, 19, 164-170.

[20] Wang, L., Feigenberg, S., Chen, L., Pasklev, K. and Ma, C.C. (2006) Benefit of three-dimensional image-guided stereotactic localization in the hypofractionated treatment of lung cancer. International Journal of Radiation Oncology Biology Physics, 66, 738-747.

[21] Wang, L., Hayes, S., Paskalev, K., Jin, L., Buyyounouski, M.K., Ma, C.C. and Feigenberg, S. (2008) Dosimetric comparison of stereotactic body radiotherapy using 4D CT and multiphase CT images for treatment planning of lung cancer: Evaluation of the impact on daily dose coverage. Radiotherapy and Oncology, 91, 314-324.

[22] Jin, L., Wang, L., Li, J., Luo, W., Feigenberg, S.J. and Ma, C.M. (2007) Investigation of optimal beam margins for stereotactic radiotherapy of lung-cancer using Monte Carlo dose calculations. Physics in Medicine and Biology, 52, 3549-3561.

[23] Babb, J., Rogatko, A. and Zacks, S. (1998) Cancer phase I clinical trials: Efficient dose escalation with overdose control. Statistics in Medicine, 17, 1103-1120.

[24] Zacks, S., Rogatko, A. and Babb, J. (1998) Optimal bayesian-feasible dose escalation for cancer phase I trials. Statistics \& probability letters, 38, 215-220.

[25] Therasse, P., Arbuck, S.G., Eisenhauer, E.A., Wanders, J., Kaplan, R.S., Rubinstein, L., Verweij, J., Van Glabbeke, M., van Oosterom, A.T., Christian, M.C. and Gwyther, S.G. (2000) New guidelines to evaluate the response to treatment in solid tumors. Journal of the National Cancer Institute, 92, 205-216.

[26] Baumann, P., Nyman, J., Hoyer, M., Gagliardi, G., Lax, I., Wennberg, B., Drugge, N., Ekberg, L., Friesland, S., Johansson, K.A., Lund, J.S., Morhed, E., Nilsson, K., Levin, N., Paludan, M., Sederholm, C., Traberg, A., Wittgren, L. and Lewensohn, R. (2008) Stereotactic body radiotherapy for medically inoperable patients with stage I non-small cell lung cancer - a first report of toxicity related to COPD/CVD in a non-randomized prospective phase II study. Radiotherapy and Oncology, 88, 359-367.

[27] Baumann, P., Nyman, J., Hoyer, M., Wennberg, B., 
Gagliardi, G., Lax, I., Drugge, N., Ekberg, L., Friesland, S., Johansson, K.A., Lund, J.A., Morhed, E., Nilsson, K., Levin, N., Paludan, M., Sederholm, C., Traberg, A., Wittgren, L. and Lewensohn, R. (2009) Outcome in a prospective phase II trial of medically inoperable stage I non-small-cell lung cancer patients treated with stereotactic body radiotherapy. Journal of Clinical Oncology, 27, 3290-3296.

[28] Fakiris, A.J., McGarry, R.C., Yiannoutsos, C.T., Papiez, L., Williams, M., Henderson, M.A. and Timmerman, R. (2009) Stereotactic body radiation therapy for earlystage non-small-cell lung carcinoma: Four-year results of a prospective phase II study. International Journal of Radiation Oncology Bilolgy Physics, 75, 677-682.

[29] Onishi, H., Araki, T., Shirato, H., Nagata, Y., Hiraoka, M., Gomi, K., Yamashita, T., Niibe, Y., Karasawa, K., Hayakawa, K., Takai, Y., Kimura, T., Hirokawa, Y., Takeda, A., Ouchi, A., Hareyama, M., Kokubo, M., Hara, R., Itami, J. and Yamada, K. (2004) Stereotactic hypofractionated high-dose irradiation for stage I nonsmall cell lung carcinoma: clinical outcomes in 245 subjects in a Japanese multiinstitutional study. Cancer, 101, 1623-1631.

[30] Onishi, H., Shirato, H., Nagata, Y., Hiraoka, M., Fujino, M., Gomi, K., Niibe, Y., Karasawa, K., Hayakawa, K., Takai, Y., Kimura, T., Takeda, A., Ouchi, A., Hareyama, M., Kokubo, M., Hara, R., Itami, J., Yamada, K. and Araki, T. (2007) Hypofractionated stereotactic radiotherapy (HypoFXSRT) for stage I non-small cell lung cancer: Updated results of 257 patients in a Japanese multi-institutional study. Journal of Thoracic Oncology, 2, S94100.

[31] Voroney, J.P.J. et al. (2008) Pain and rib fracture after stereotactic radiotherapy for peripheral non-small cell lung cancer. International Journal of Radiation Oncology Biology Physics, 72, S35-36.

[32] Dunlap, N.E. et al. (2008) Chest wall volume receiving more than 30 Gy predicts risk of severe pain and/or rib fracture following lung SBRT. International Journal of Radiation Oncology Biology Physics, 72, S36.

[33] Stephens, K.L. et al. (2008) A comparison of Stereotactic Body Radiation (SBRT) fractionation schedules for stage I non-small cell lung cancer (NSCLC): The cleveland clinic experience. International Journal of Radiation Oncology Biology Physics, 72, S38-39.

[34] Forquer, J.A. et al. (2008) Brachial Plexopathy (BP) from Stereotactic Body Radiotherapy (SBRT) in earlystage NSCLC: Dose-limiting toxicity in apical tumor sites. International Journal of Radiation Oncology Biology Physics, 72, S36.

[35] Timmerman, R., Paulus, R., Galvin, J.M., Michalski, J., Straube, W.L., Bradley, J., Fakiris, A., Bezjak, A., Videtic, G. and Choy, H. (2007) Toxicity analysis of RTOG 0236 using stereotactic body radiation therapy to treat medically inoperable early stage lung cancer patients. International Journal of Radiation Oncology Bilolgy Physics, 69, S86.

[36] Guerrero, M. and Li, X.A. (2004) Extending the linear-quadratic model for large fraction doses pertinent to stereotactic radiotherapy. Physics in Medicine and Biology, 49, 4825-4835.

[37] Nataf, F., Schlienger, M., Liu, Z., Foulquier, J.N., Gres, B., Orthuon, A., Vannetzel, J.M., Escudier, B., Meder, J.F., Roux, F.X. and Touboul, E. (2008) Radiosurgery with or without A 2-mm margin for 93 single brain metastases. International Journal of Radiation Oncology Bilolgy Physics, 70, 766-772. 